\title{
Benzyne arylation of oxathiane glycosyl donors
}

\author{
Martin A. Fascione and W. Bruce Turnbull
}

\author{
Preliminary Communication \\ Address: \\ School of Chemistry, University of Leeds, Leeds, LS2 9JT, UK \\ Email: \\ W. Bruce Turnbull - w.b.turnbull@leeds.ac.uk \\ * Corresponding author \\ Keywords: \\ benzyne; 1,2-cis-glycosides; glycosyl acetates; oxathiane glycosyl \\ donors; stereoselective glycosylations
}

Open Access

\author{
Beilstein Journal of Organic Chemistry 2010, 6, No. 19 \\ doi:10.3762/bjoc.6.19 \\ Received: 27 November 2009 \\ Accepted: 11 February 2010 \\ Published: 22 February 2010 \\ Guest Editor: T. K. Lindhorst \\ (C) 2010 Fascione and Turnbull; licensee Beilstein-Institut. \\ License and terms: see end of document.
}

\begin{abstract}
The arylation of bicyclic oxathiane glycosyl donors has been achieved using benzyne generated in situ from 1-aminobenzotriazole (1-ABT) and lead tetraacetate. Following sulfur arylation, glycosylation of acetate ions proceeded with high levels of stereoselectivity to afford $\alpha$-glycosyl acetates in a 'one-pot' reaction, even in the presence of alternative acceptor alcohols.
\end{abstract}

\section{Introduction}

Carbohydrates play important roles in many biological processes including tumour metastasis [1,2], bacterial and viral recognition [3-5], and the immunological response [6-8]. In order to obtain pure samples of oligosaccharides for biological studies, carbohydrate chemists must overcome the myriad challenges presented by their complex synthesis. The most important challenge is control over the stereoselectivity of reactions at the anomeric centre; in particular for the stereoselective synthesis of 1,2-cis-glycosides [9]. This area has been the subject of much fervent study in the last two decades, and has led to many significant developments $[10,11]$. However, despite these advances, modern synthetic carbohydrate chemistry has still to provide a general method for the efficient synthesis of 1,2-cis- $\alpha$-glycosidic linkages.

In 2005 Boons and co-workers reported an elegant chiral auxiliary-based glycosylation protocol for the synthesis of 1,2-cis- $\alpha$ glycosides [12]. Completely stereoselective glycosylation was achieved when a thiophenyl-containing chiral auxiliary was at- tached to $O-2$ of an imidate glycosyl donor 1 (Scheme 1a). Low temperature ${ }^{1} \mathrm{H}$ NMR spectroscopy studies confirmed the formation of a quasi-stable trans-decalin intermediate 2, which was able to cause glycosylation to take place from the $\alpha$-face of the glycosyl donor. We sought to improve this strategy and recently reported a novel class of bicyclic oxathiane ketal donors 5 containing an inbuilt $\alpha$-directing group (Scheme 1b) [13]. The principal objective of our approach was to develop a thioglycoside donor that could mimic the key trans-decalin intermediate 2 by using the sulfur-containing auxiliary as both the anomeric leaving group and $\alpha$-directing participating group. An efficient synthesis of the key bicyclic intermediate was achieved starting from a simple thioglycoside $\mathbf{4}$ where the essential $\beta$-sulfur linkage was already installed, followed by a regio and stereoselective cyclisation onto the $O-2$ position to afford oxathiane glycosyl donor framework 5 . The oxathiane ketal donor $\mathbf{5}$ is then already pre-organised to give a 1,2-cis directing group upon activation, and afford 1,2-cis-glycosides 7 on alcohol addition. 
a)

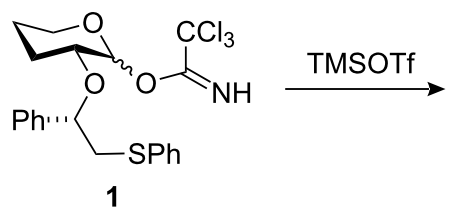<smiles></smiles>

$\mathrm{SPh}$

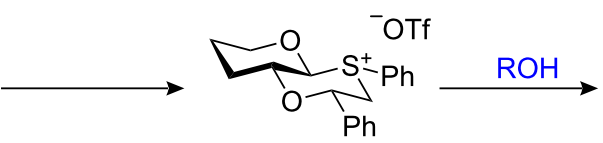

2

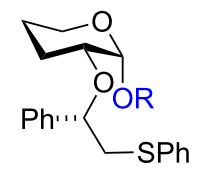

3

b)

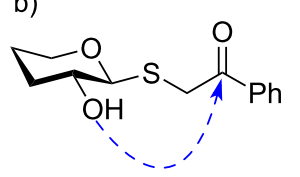

4

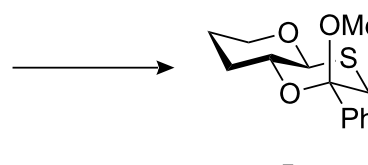

5

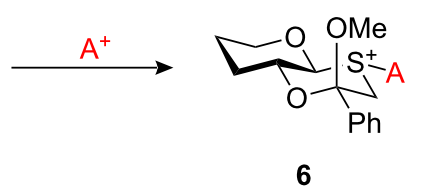

6
(S)

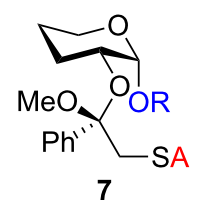

Scheme 1: a) Boons' chiral auxiliary-based approach to a-stereoselective glycosylations. b) Modified strategy for stereoselective glycosylations using oxathiane ketal glycosyl donors 5 .

Following the synthesis of the oxathiane ketal glycosyl donors $\mathbf{5}$, activation of the $\beta$-thioglycoside linkage was necessary to form the key trans-decalin sulfonium ion $\mathbf{6}$, and turn the $\alpha$-directing participating group into an anomeric leaving group reactive enough to partake in glycosylations. Thioglycosides are widely used as glycosyl donors [14,15], and many different reagents are available for their activaton including $\mathrm{N}$-iodosuccinimide (NIS)/TMSOTf [16], dimethyl(methylthio)sulfonium trifluoromethanesulfonate (DMTST) [17,18], PhSeOTf [19], $\mathrm{MeS}-\mathrm{SMe} / \mathrm{Tf}_{2} \mathrm{O}$ [20], and MeOTf [21-23]. However, in order to recreate the reactive sulfonium ion used by Boons, it would be necessary to activate the anomeric sulfur with a phenyl group. Herein we describe our synthetic endeavours to achieve this goal and the first use of benzyne as an activating agent for thioglycosides [24].

\section{Results and Discussion}

The method chosen for in situ benzyne (9) generation was the reaction of 1-aminobenzotriazole (1-ABT) (8) with lead tetraacetate by the procedure pioneered by Rees and co-workers (Scheme 2) [25-28]. The low reaction temperature was expected to be compatible with stereoselective glycosylation. Following

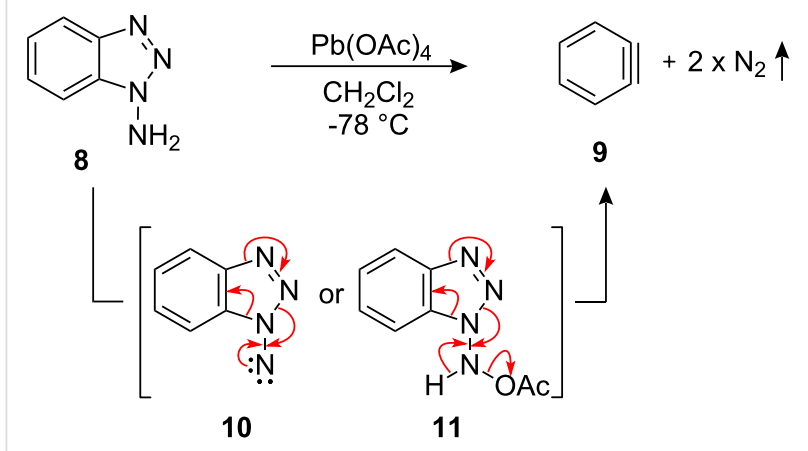

Scheme 2: Benzyne generation from 1-ABT. the reaction of 1-ABT (8) with lead tetraacetate, benzyne (9) formation is believed to occur via degradation of either an $\mathrm{N}$-nitrene intermediate $\mathbf{1 0}$ or an $\mathrm{N}$-acetate substituted intermediate 11 the driving force for which is the release of di-nitrogen [29].

The synthesis of oxathiane ketal $\mathbf{1 3}$ was achieved in two steps from thioglycoside $\mathbf{1 2}$ as previously reported, followed by protection to afford the acetylated oxathiane ketal $\mathbf{1 4}$ or the benzylated oxathiane ketal 15 (Scheme 3) [13]. Ketal 13 was also reduced to the novel oxathiane ether $\mathbf{1 6}$ in $89 \%$ yield, and

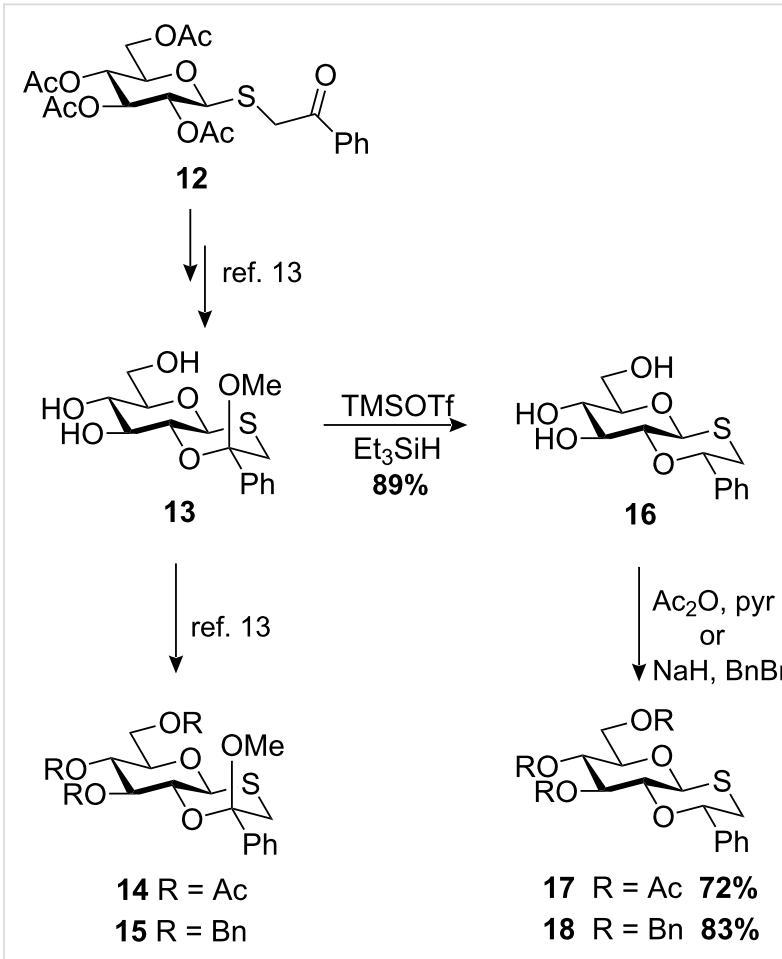

Scheme 3: Oxathiane donor synthesis. 
a)

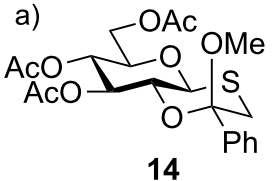

14

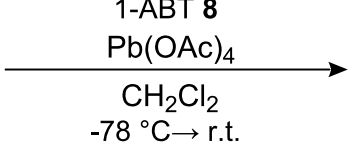

$\mathrm{CH}_{2} \mathrm{Cl}_{2}$

$78^{\circ} \mathrm{C} \rightarrow$ r.t.

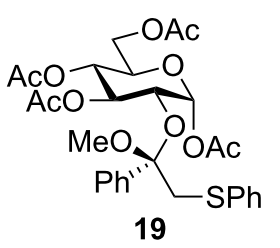

$82 \%, \alpha: \beta>98: 2$

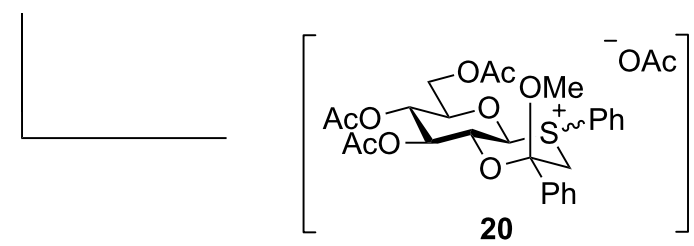

b)

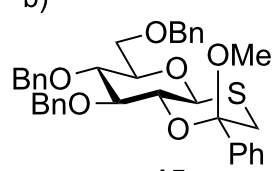

15

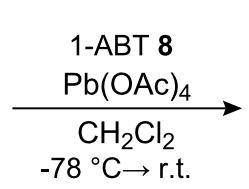

$-78^{\circ} \mathrm{C} \rightarrow$ r.t.
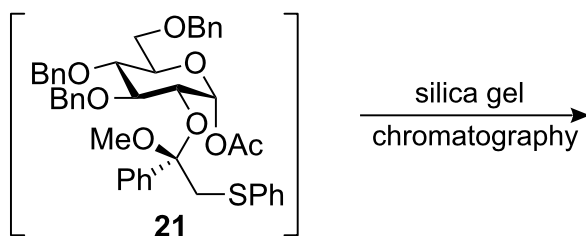

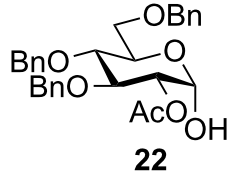

$70 \%, \alpha: \beta>98: 2$

c)

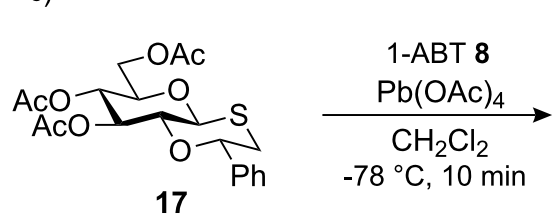

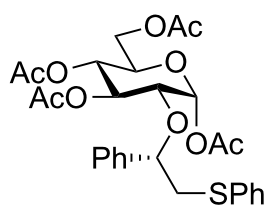

23<smiles>CCOc1ccccc1NNCCCO</smiles>

ii) $\mathrm{Cl}_{3} \mathrm{CCN}, \mathrm{DBU}$

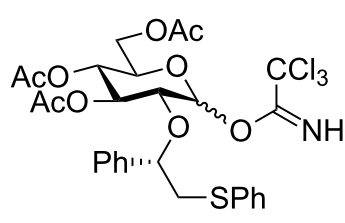

24

$62 \%, \alpha: \beta>98: 2$

d)
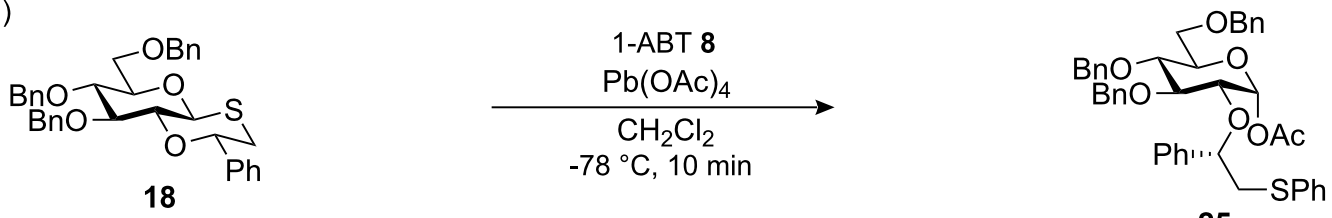

25

$57 \%, \alpha: \beta 96: 4$

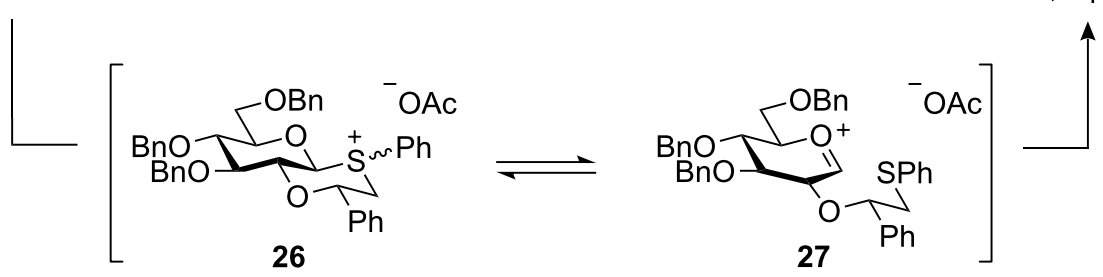

Scheme 4: Arylation/acetate glycosylation of oxathiane glycosyl donors.

protected to afford acetylated oxathiane ether $\mathbf{1 7}$ and benzylated oxathiane ether 18 in yields of $72 \%$ and $83 \%$, respectively.

With the oxathiane ketal and ether donors in hand, initial studies focussed on benzyne arylation in the absence of any alcohol acceptor. Unexpectedly, when activated under the reaction conditions, acetylated oxathiane ketal 14 afforded $\alpha$-glycosyl acetate 19 stereoselectively in $82 \%$ yield (Scheme $4 a$ ).
Presumably, the mechanism proceeds via sulfur arylation with benzyne to afford putative phenyl sulfonium ion $\mathbf{2 0}$, followed by glycosylation of the acetate anion. The very high $\alpha$-stereoselectivity ( $\alpha: \beta>98: 2)$ of the reaction was in line with selectivities previously observed for intermediate oxathiane sulfonium ions [13]. When the reaction was repeated in the absence of 1-ABT, the starting material was unchanged, thus precluding the possibility of initial sulfur activation by lead tetraacetate. 
Arylation of benzylated oxathiane ketal $\mathbf{1 5}$ under identical conditions also afforded $\alpha$-glycosyl acetate $\mathbf{2 1}$ as the sole crude product as evidenced by ${ }^{1} \mathrm{H}$ NMR spectroscopy (Scheme 4b). However, only $\alpha$-hemiacetal 22 was isolated in $70 \%$ yield following purification by flash silica chromatography [30]. Cleavage of the acyclic $O-2$ ketal on glycosyl acetate 21, followed by acetyl transfer from $O-1$ to $O-2$ could account for this transformation [31].

Arylation/acetate glycosylation using oxathiane ether donor $\mathbf{1 7}$ also occurred readily to give the $\alpha$-glycosyl acetate 23 in $62 \%$ yield with complete anomeric control (Scheme 4c). It is of interest to note that glycosyl acetate $\mathbf{2 3}$ has been reported previously by Boons and co-workers as an advanced intermediate in their synthesis of trichloroacetimidate donor 24 bearing a 2-O(1S)-phenyl-2-(phenylsulfanyl)ethyl group (Scheme 4c) [12]. Although the benzyne arylation method does not allow us to access $\alpha$-glycosides directly, it could be beneficial as an alternative route to glycosyl donors bearing the Boons' participating group. This strategy has the advantage of utilising the inherent chirality of the sugar to determine the stereochemistry of the key benzylic centre in the chiral auxiliary, and also facilitates regioselective attachment of the auxiliary group to $O-2$.

The benzylated oxathiane ether $\mathbf{1 8}$ also afforded a glycosyl acetate $\mathbf{2 5}$ in $57 \%$ yield but on this occasion as a 96:4 ( $\alpha: \beta)$ mixture of anomers (Scheme 4d). This slight drop in stereoselectivity is consistent with the increased reactivity of benzylated relative to acetylated thioglycoside donors $[13,32]$, commonly attributed to greater stabilisation of the developing positive charge on an oxacarbenium intermediate $\mathbf{2 7}$ on the reaction pathway. Overall, reactions using the oxathiane ether donors proceeded more rapidly than those with the oxathiane ketal donors, indicating that the methoxy substituent moderates the reactivity of the glycosyl donors.

Attempts to intercept putative phenyl sulfonium ions such as $\mathbf{2 0}$ and $\mathbf{2 6}$ in glycosylation reactions with other acceptors prior to acetate glycosylation were in vain, presumably due to the high effective concentration of acetate anions in solution. Therefore, alternative oxidising agents for benzyne formation were also investigated in the hope that glycosylation with external alcohols would be easier to achieve if the phenyl sulfonium ion was formed with a less reactive counter ion. However, oxidation of $1-\mathrm{ABT}$ in the presence of ketal 14 with NIS [33], or hypervalent iodine (III) with either bis(acetoxy)iodobenzene [PhI(OAc) $)_{2}$ [34] or bis(trifluoroacetoxy)iodobenzene $\left[\mathrm{PhI}\left(\mathrm{OCOCF}_{3}\right)_{2}\right]$ were unsuccessful [35], resulting in at best only trace amounts of phenyl sulfonium ion formation. Under these reaction conditions, nitrogen evolution and presumably benzyne formation, was much slower than when using lead tetraacetate as the oxidising agent. Further studies using the more reactive Zefirov's reagent ( $\mu$-oxobis[(trifluoromethanesulfonato)(phenyl)iodine]) [36,37] were also undertaken. Preliminary results were promising yielding simple $\alpha$-glycosides and a full study will be reported in due course. Unfortunately, attempted extension of the arylation/acetate glycosylation methodology to conventional thiophenyl glycosyl donors was disappointing, as experiments either did not proceed to completion, or were hampered by oxidation of the thiophenyl group in the presence of lead tetraacetate [38].

\section{Conclusion}

In conclusion, it has been demonstrated that benzyne arylation of novel oxathiane glycosyl donors can be achieved using a combination of 1-ABT and lead tetraacetate. Following arylation, glycosylation with an acetate anion takes place with a high degree of stereoselectivity to afford 1,2-cis- $\alpha$-acetates.

\section{Supporting Information}

Supporting Information File 1 features full experimental data for the synthesis of compounds 16-19, 22, 23 and 25.

\section{Supporting Information File 1}

Experimental data for the synthesis of compounds 16-19, 22, 23 and 25.

[http://www.beilstein-journals.org/bjoc/content/ supplementary/1860-5397-6-19-S1.pdf]

\section{Acknowledgements}

The authors would like to thank The Royal Society, the EPSRC and the University of Leeds for funding. MAF is the recipient of a Henry Ellison Scholarship, and WBT is a Royal Society University Research Fellow.

\section{References}

1. Liu, F. T.; Rabinovich, G. A. Nat. Rev. Cancer 2005, 5, 29-41. doi:10.1038/nrc1527

2. Sasisekharan, R.; Shriver, Z.; Venkataraman, G.; Narayanasami, U. Nat. Rev. Cancer 2002, 2, 521-528. doi:10.1038/nrc842

3. Kitov, P. I.; Sadowska, J. M.; Mulvey, G.; Armstrong, G. D.; Ling, H.; Pannu, N. S.; Read, R. J.; Bundle, D. R. Nature 2000, 403, 669-672. doi:10.1038/35001095

4. Weis, W. I.; Drickamer, K. Annu. Rev. Biochem. 1996, 65, 441-473. doi:10.1146/annurev.bi.65.070196.002301

5. Kinjo, Y.; Wu, D.; Kim, G. S.; Xing, G. W.; Poles, M. A.; Ho, D. D.; Tsuji, M.; Kawahara, K.; Wong, C. H.; Kronenberg, M. Nature 2005, 434, 520-525. doi:10.1038/nature03407

6. Ragupathi, G. Cancer Immunol. Immunother. 1996, 43, 152-157. doi:10.1007/s002620050316 
7. Ragupathi, G.; Park, T. K.; Zhang, S. L.; Kim, I. J.; Graber, L.; Adluri, S.; Lloyd, K. O.; Danishefsky, S. J.; Livingston, P. O. Angew. Chem., Int. Ed. Engl. 1997, 36, 125-128. doi:10.1002/anie.199701251

8. Reitter, J. N.; Means, R. E.; Desrosiers, R. C. Nat. Med. 1998, 4, 679-684. doi:10.1038/nm0698-679

9. Paulsen, H. Angew. Chem., Int. Ed. Engl. 1982, 21, 155-224. doi:10.1002/anie.198201553

10. Xiangming, Z.; Schmidt, R. R. Angew. Chem., Int. Ed. 2009, 48, 1900-1934. doi:10.1002/anie.200802036

11. Demchenko, A. V. Curr. Org. Chem. 2003, 7, 35-79. doi:10.2174/1385272033373175

12. Kim, J.-H.; Yang, H.; Park, J.; Boons, G.-J. J. Am. Chem. Soc. 2005, 127, 12090-12097. doi:10.1021/ja052548h

13. Fascione, M. A.; Adshead, S. J.; Stalford, S. A.; Kilner, C. A.; Leach, A. G.; Turnbull, W. B. Chem. Commun. 2009, 5841-5843. doi:10.1039/b913308a

14. Turnbull, W. B.; Fascione, M. A.; Stalford, S. A. Sci. Synth. 2007, 29, 923-969.

15. Garegg, P. J. Adv. Carbohydr. Chem. Biochem. 1997, 52, 179-205. doi:10.1016/S0065-2318(08)60091-8

16. Kartha, K. P. R.; Field, R. A. Synthesis and activation of carbohydrate donors: thioglycosides and sulfoxides. In Best Synthetic Methods: Carbohydrates; Osborn, H. M. I., Ed.; Elsevier Science Ltd: Amsterdam, 2003; pp 121-145.

17. Fugedi, P.; Garegg, P. J. Carbohydr. Res. 1986, 149, C9-C12. doi:10.1016/S0008-6215(00)90385-9

18. Garegg, P. J.; Helland, A. C. J. Carbohydr. Chem. 1993, 12, 105-117. doi:10.1080/07328309308018544

19. Mori, M.; Ito, Y.; Ogawa, T. Carbohydr. Res. 1989, 192, 131-146. doi:10.1016/0008-6215(89)85173-0

20. Fugedi, P.; Tatai, J. Org. Lett. 2007, 9, 4647-4650. doi:10.1021/ol702139u

21. Ito, Y.; Ogawa, T. J. Am. Chem. Soc. 1997, 119, 5562-5566. doi:10.1021/ja964093p

22. Ito, Y.; Ohnishi, Y.; Ogawa, T.; Nakahara, Y. Synlett 1998, 1102-1104. doi:10.1055/s-1998-1894

23. Ishiwata, A.; Munemura, Y.; Ito, Y. Eur. J. Org. Chem. 2008, 4250-4263. doi:10.1002/ejoc.200800249

24. Nakayama, J.; Akimoto, K. Sulfur Rep. 1994, 16, 61-111. doi:10.1080/01961779408048966 See for a review of benzyne reactions with sulfur compounds.

25. Campbell, C. D.; Rees, C. W. Proc. Chem. Soc., London 1964, 296.

26. Campbell, C. D.; Rees, C. W. J. Chem. Soc. C 1969, 742-747. doi:10.1039/J39690000742

27. Campbell, C. D.; Rees, C. W. J. Chem. Soc. C 1969, 748-751. doi:10.1039/J39690000748

28. Fleet, G. W. J.; Fleming, I. J. Chem. Soc. C 1969, 1758-1763. doi:10.1039/j39690001758

See for pyridyne synthesis from $\mathrm{N}$-aminotriazole-pyridine and lead tetraacetate.

29. Birkett, M. A.; Knight, D. W.; Giles, R. G.; Mitchell, M. B. J. Chem. Soc., Perkin Trans. 1 1998, 2301-2306. doi:10.1039/a803251c

30. Schmidt, R. R.; Effenberger, G. Carbohydr. Res. 1987, 171, 59-79. doi:10.1016/S0008-6215(00)90879-6

31. Lindhorst, T. K. Essentials of Carbohydrate Chemistry and Biochemistry, 2nd ed.; Wiley VCH: Weinheim, Germany, 2003; pp 52 ff.
32. Zhang, Z. Y.; Ollmann, I. R.; Ye, X. S.; Wischnat, R.; Baasov, T.; Wong, C. H. J. Am. Chem. Soc. 1999, 121, 734-753. doi:10.1021/ja982232s

33. Knight, D. W.; Little, P. B. J. Chem. Soc., Perkin Trans. 12000 , 2343-2355. doi:10.1039/b001834I

34. Campbell, C. D.; Rees, C. W. J. Chem. Soc. C 1969, 752-756. doi:10.1039/J39690000752

35. Moriarty, M. R. J. Org. Chem. 2005, 70, 2893-2903. doi:10.1021/jo050117b See for a review of organohypervalent iodine.

36. Zefirov, N. S.; Zhdankin, V. V.; Dan'kov, Y. V.; Koz'min, A. S. J. Org. Chem. USSR 1984, 20, 401.

37. Hembre, R. T.; Scott, C. P.; Norton, J. R. J. Org. Chem. 1987, 52, 3650-3654. doi:10.1021/jo00392a028

38. Banerji, K. K. J. Chem. Soc., Perkin Trans. 2 1991, 759-763. doi:10.1039/p29910000759

\section{License and Terms}

This is an Open Access article under the terms of the Creative Commons Attribution License

(http://creativecommons.org/licenses/by/2.0), which permits unrestricted use, distribution, and reproduction in any medium, provided the original work is properly cited.

The license is subject to the Beilstein Journal of Organic Chemistry terms and conditions:

(http://www.beilstein-journals.org/bjoc)

The definitive version of this article is the electronic one which can be found at: doi:10.3762/bjoc.6.19 